\title{
Field study on the effect of aluminum silicate adsorbent on performance of 51 weeks old broiler breeder chickens
}

\author{
G. A. Zohair ${ }^{1}$, M. M. Amer ${ }^{2 *}$, A. E. Hanafei ${ }^{3}$ \\ ${ }^{I}$ Department of Animal Production, Faculty of Agriculture, Sana'a University, Yemen; ${ }^{2}$ Department \\ of Poultry Diseases, Faculty of Veterinary Medicine, Cairo University, Egypt and ${ }^{3}$ El-Watania \\ Poultry Company, Giza, Egypt
}

\begin{abstract}
In 9 weeks field study, a total of 14100 (Ross broiler breeders) 51 weeks-old chickens fed on the same ration, placed in 2 houses $(6600$ female +450 male / house). Birds of house 1 were treated with antimycotoxin adsorbent aluminum silicate (G-V-tox®) $5 \mathrm{kgm} / \mathrm{ton}$, while those of house 2 were kept as non treated controls. Productivity and reproductivety parameters were calculated for comparison. Treated flock showed improved average egg production (Average 62.2\%/week) compared with non treated (Average 61.7\%/week), but all still lower than farm stander (Average 76.4\%/week). Marked improvement was in the $1^{\text {st }} 3$ weeks (51-53) of treatment only. Total 9 weeks production declined was $5.5 \%$ and $8.4 \%$ in control and silicate treated flock; with weekly average of 0.61 , and 0.93 ; respectively. Control flock was slower in decline of production $(0.61 \% /$ week $)$ than treated flock $(0.93 \%$ /week). Average weekly egg production and hatching eggs/ hen in treated flock was lower than standard and higher than non treated. Hatchery parameters of treated were improved in treated at the first 3 weeks post treatment. The fertility was higher in aluminum silicate treated group $(\mathbf{7 7 . 2 \%})$, than the untreated one $(\mathbf{7 2 . 1 9 \%})$. The hatchability was in silicate treated $(63.66 \%)$ versus $(62.25 \%)$ in the untreated control. Culls \% in hatched chicks was $1.91 \%$ in treated flock and lower than in non treated $(2.85 \%)$. Difference percentage between fertility and hatchability of G.V. tox treated chickens was $(10.84 \%)$ higher than untreated control $(16 \%)$. The number of marketable chicks $\mathbf{1 1 0 0}$ was also improved in treated than non treated. In conclusion, our field study cleared that administration of Silicate in ration for treatment of broiler breeders resulted in an improved production and hatchery performance as compared with non medicated control. However; it did not restore it to the farm stander. Consequently the results indicated that we still in need for more effective products to be used to control mycotoxins in breeder chicken.
\end{abstract}

Mycotoxinis are toxic and carcinogenic metabolites of fungi that occur in poultry feed under conditions of high temperature and high moisture (Bacon, et al., 1973). Aflatoxins are toxic metabolic product of $A$. flavus, $A$. parasiticus, and Penicillium puberulum, while Ochratoxin A (OA) is the most toxic product of Penicillium viridicatum and Aspergillus ochraceous (Dwivedi and Burns, 1986) causing disease conditions (Wyatt and Hamilton, 1975; Abdullah and Lee, 1981; Choudary and Rao, 1982; Jones et al., 1982; Hetzel et al., 1984; Dafalla, et al., 1987; Shoyinka et al., 1987; Anjum, 1994; Saif et al., 2003).

Nowadays, hundreds of mycotoxins are recognized (Uraguchi and Yamazaki, 1978). The synergistic interaction between OA and

Aflatoxins was recorded (Huff et al., 1983 ,1992). Mycotoxins affects poultry production by lowering weight gain (Asplin and Carnaghan, 1961), feed efficiency, egg production (Prior

* Corresponding author. Tel.: +20 012 1770699;

E-mail address: Profdramer@yahoo.com

(Mohammed M. Amer). and Sisodia, 1978; Bryden et al., 1980) and reproductive performance, increased susceptibility to infectious disease (Wyatt and Hamilton, 1975; Bryden et al., 1980) immunosuppression (Pier, 1973; Burns and Dwivedi, 1986; El-Karim et al., 1991), vaccination failure (Anjum, 1994; Azzam and Gabal, 1997,1998; Bunaciu et al., 1998) interaction with mineral metabolism (Gardiner and Oldroyd, 1965), low hatchability due to embryonic death in broiler breeders (Cottier, et al., 1969; Choudhury et al., 1971; Niemiec et al., 1995) and impaired egg production (Kratzer et al., 1969 and Huff et al., 1975).

Many commercial products including mycotoxin-binding agents are used for detoxification contaminated feeds. Inorganic mineral adsorbents as silica containing products are more practical and economical feed additives to ameliorate the toxic effects of mycotoxins and ochratoxin A (Prior and Sisodia, 1978; Huff et al., 1992; Kubena et al., 1993; Harvey et al., 1993; Bailey et al., 1998). 
This study was carried out as a field trial to evaluate the preventive value of commercial products including Aluminum silicate as adsorbent (G.V- tox.) in Ross broiler breeders where reproductivety and hatchery parameters were determined during period of production to evaluate the total effect income of breeder flocks.

\section{Materials and methods}

Chicken. A total of 14100 Ross broiler breeders 51 weeks old chickens including 13200 females and 900 males housed in 2 closed houses; approximately 6600 females with 450 males in each house.

Ration. Mash, corn, Soya, 16\% protein broiler breeder layer ration manufactured according to Ross breeders management guide and adjusted to fulfill the requirements of layer breeder according to (NRC, 1984).

Detection of mycotoxins. The used ration was analyzed for detection of mycotoxins according to (Soares and Rodrigez-Amaya, 1989) and found to contain Aflatoxins (4 ppb) and Ochratoxin (2.45 ppb). The aflatoxin content of ration were analyzed by using immunoaffinity columns (Vicam AflaTest ${ }^{\circledR}$ Affinity Column) and quantified by high performance liquid chromategraphy (HPLC) (Agillent 1100 Series).

Diagnosis of maycotoxicosis. In relation to low reproductively and detection of toxins in ration dead cases had lesions including hydropericardium and ascites. Liver was shrunken firm nodular or yellow fatty, ocher discoloration, hemorrhages in the capsular surface, distended gall bladder, white foci also seen in hepatic tissues. Kidneys were pale with increased urates and catarrhal enteritis (Saif et al., 2003).

Detoxifying products. The detoxifying commercial product G-V-tox ${ }^{\circledR}$ (aluminum silicate adsorbents) was used according to producer's recommendations in ration of breeder chickens in rate of $5 \mathrm{~kg} /$ ton for 9 successive weeks.

Performance. The calculated parameters in this field study were compared with a control untreated house and farm standerd for Ross breeder chickens for 9 weeks post medication between 51 and 59 weeks of age. Hen day production and hatching eggs were determined to evaluate the effect of used drug on productivity, while hatchery parameters including fertility and hatchability, difference between fertility and hatchability; culled chicks \%, number of marketable chicks/1000 housed hens/day and weekly chicks / hen were calculated as average during the whole production period.

Experimental design. Both hens and cockerels were fed on the same ration. Breeder house 1 was fed with aluminum silicate in ratio of $5 \mathrm{~kg} /$ ton of ration, while house 2 was kept as control non treated. Obtained results are shown in (Table 1, 2, Fig. 1-4).

\section{Results and Discussion}

There are various approaches to control or combat mycotoxin problems. The simplest method based on the prevention or minimizes formation of mycotoxins in ration by good storage and prevention of grain damage during processing, shipping and handling (Dawson, 2001; Saif et al., 2003). Silica adsorbents as more practical and economical feed additives are added to poultry feeds to ameliorate the toxic effects of mycotoxins (Prior and Sisodia, 1978; Huff et al., 1992; Kubena et al., 1993; Harvey et al.,1993; Bailey et al., 1998).

Weekly egg production rates were declined gradually as a physiological state, but this production was lower as compared to Ross Farm standard. The condition was diagnosed as a result of mycotoxicosis. As decrease in egg production was reported as a sign of mycotoxicosis in breeder chickens (Choudhury et al., 1971; Prior and Sisodia, 1978; Page et al., 1980; Niemiec et al., 1995).

Administration of silicate adsorbent to breeder chicken flock for 9 weeks (from 51-59) resulted in increase in weekly egg production than control flock (Table1, Fig. 1). Treated flock showed improved average egg production (Average 62.2\%/week) compared with non treated (Average 61.7\%/week), but all still lower from farm standard (Average 76.4\%/week). Marked increased egg production was seen in the $1^{\text {st }} 3$ weeks $(51-53)$ of treatment only. Production declined in 9 weeks reached $5.5 \%$ and $8.4 \%$ in control and silicate treated with average weekly decline 0.61 and 0.93 ; respectively. Control flock was slower in decline than treated flocks. This result indicated that silicate was of value in amelioration of the toxic effects of mycotoxins and ochratoxin A (Prior and Sisodia, 1978; Huff et al., 1992; Kubena et al., 1993; Harvey et al., 1993; Bailey et al., 1998).

Average weekly cumulative egg production/ 

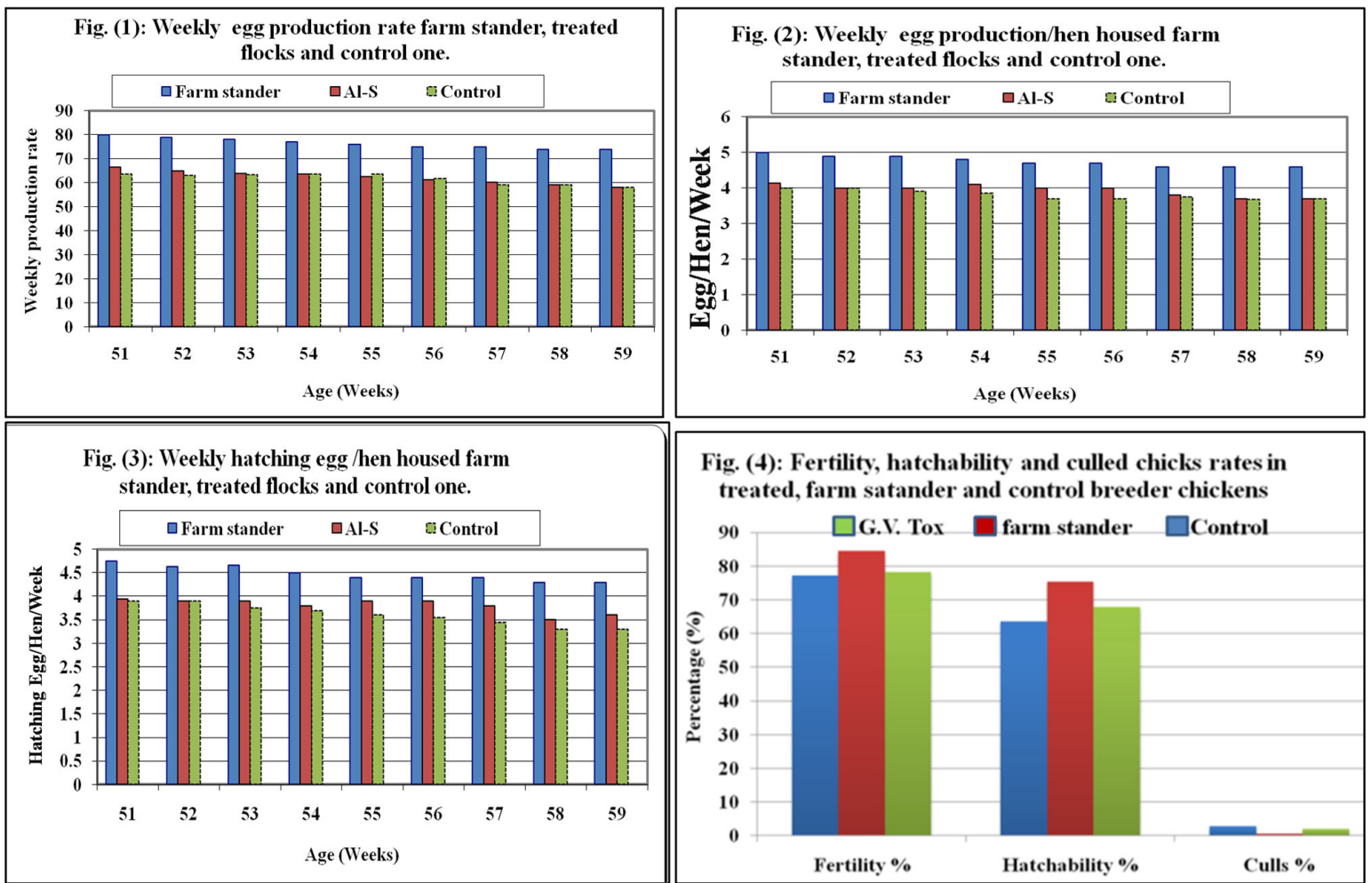

Table (1): Weekly average hen egg production, egg produced and hatching eggs/hen housed/week of treated flock compared with farm standerd and non treated control.

\begin{tabular}{cccccccccc}
\hline $\begin{array}{c}\text { Age } \\
\text { I } \\
\text { weeks }\end{array}$ & \multicolumn{3}{c}{$\begin{array}{c}\text { Weekly hen } \\
\text { production }\end{array}$} & \multicolumn{3}{c}{ produced eggs / hen housed } & \multicolumn{3}{c}{$\begin{array}{c}\text { Hatching eggs / hen } \\
\text { / woek }\end{array}$} \\
\cline { 2 - 10 } housed / week \\
\hline 51 & 80.0 & Al. S.** & Control & F. St. & Al. S & Control & F. St.* & Al. S & Control \\
52 & 79.0 & 64.9 & 63.5 & 5.00 & 4.13 & 4.00 & 4.75 & 3.95 & 3.90 \\
53 & 78.0 & 64.0 & 63.4 & 4.90 & 4.00 & 4.00 & 4.64 & 3.90 & 3.90 \\
54 & 77.0 & 63.5 & 63.6 & 4.80 & 4.00 & 3.90 & 4.66 & 3.90 & 3.75 \\
55 & 76.0 & 62.5 & 63.7 & 4.70 & 4.00 & 3.85 & 4.50 & 3.80 & 3.70 \\
56 & 75.0 & 61.2 & 61.7 & 4.70 & 4.00 & 3.70 & 4.40 & 3.90 & 3.55 \\
57 & 75.0 & 60.1 & 59.0 & 4.60 & 3.80 & 3.75 & 4.40 & 3.80 & 3.45 \\
58 & 74.0 & 59.2 & 59.1 & 4.60 & 3.70 & 3.68 & 4.30 & 3.50 & 3.30 \\
59 & 74.0 & 58.1 & 58.0 & 4.60 & 3.70 & 3.70 & 4.30 & 3.60 & 3.30 \\
Av. /w \# & 76.4 & 62.2 & 61.7 & 4.76 & 3.94 & 3.81 & 4.48 & 3.81 & 3.61 \\
Diff \#\# & 6.0 & 8.4 & 5.5 & 0.40 & 0.43 & 0.30 & 0.45 & 0.45 & 0.60 \\
Dic/w*** & 0.66 & 0.93 & 0.61 & 0.04 & 0.05 & 0.03 & 0.05 & 0.05 & 0.07 \\
\hline
\end{tabular}

* F. St.: Farm Stander ** Al. S : Aluminum Silicate $\quad * * *$ Dic/w: Average weekly decline.

\# Av../w: average weekly production. \#\# Diff: production of week 51- production of week 59.

Table (2): Fertility, hatchability and difference in-between, culls, marketable chicks/1000 in treated and control breeder chickens.

\begin{tabular}{lccccc}
\hline Treatment & Fertility \% & hatchability $\%$ & \multicolumn{3}{c}{ Fert. - Hatch. Culls \% } \\
\hline Farm stander & 84.50 & 75.33 & 8.17 & 0.53 & 749.8 \\
Al. S. & 77.20 & 63.66 & 13.54 & 1.91 & 667.36 \\
Control. & 78.25 & 62.25 & 16.00 & 2.85 & 637.71 \\
\hline
\end{tabular}


hen housed in the treated flock was higher (3.94/hen) than non treated (3.81/hen) and both were lower than standard $(4.76 /$ hen $)$. Treated flock show higher and stale average cumulative egg production $\left(4.0\right.$ eggs / hen) from the $2^{\text {nd }}$ week (week 52) to the weeks $56^{\text {th }}$ week of age. In contrast non treated chickens showed gradual weekly decrease. Generally, the silicate treated birds were higher in egg production (Table 1, Fig 2).

Cumulative hatching egg/hen housed (Table 1, Fig. 3) of treated and non treated control were lower than the standard level. The treated group showed the higher average cumulative hatching egg (3.81 hatching egg/hen) than non treated (3.61 hatching egg/hen). The treated flock showed improved hatching egg/hen (3.95) in the $51^{\text {st }}$ weeks and remains higher till the $59^{\text {th }}$. This result proved that the determined aflatoxin and Ocratoxin in ration had adverse effect on egg quality (Page, et al., 1980; Prior and Sisodia, 1978; Prior,et al., 1981; Niemiec et al.,1995). Also, aflatoxins affect calcium and phosphorus metabolism by altering the metabolism of vitamin D3 and parathyroid hormone as reported by (Glahn et al., 1991). The periodical improvement in number of hatched eggs can be attributed to the limited effect of Silica in removal of the Ocratoxin A or synergism of Aflatoxin and Ocratoxin A (Huff et al., 1983, 1992).

Hatchery parameters in (Table 2) including fertility, hatchability and culled chicks of treated with control flock at the first 3 weeks post treatment as average rates; the higher fertility in silica treated flocks $(77.2 \%)$ and the untreated control show $72.19 \%$ fertility. This result indicated the effect of mycotoxins on fertility as reported by (Ortalatli et al., 2002) who detected microscopically abnormal spermatozoa and cessation spermatogenesis in seminiferous tubules in aflatoxin feed cocks.

The hatchability was $63.66 \%$ in treated; while it was $62.25 \%$ in untreated control. Percentages of culls in hatched chicks were the lower in non treated flock $(1.91 \%)$ than in treated flocks $(2.85 \%)$. Loss of hatchability was attributed to embryonic death in broiler breeders and leghorns induced by aflatoxin (Cottier et al., 1969; Howarth and Wyatt, 1976) and Ocratoxin A (Oloudhury et al., 1971; Prior and Sisodia, 1978; Tohala, 1983; Niemiec et al., 1995) that had teratogenic effect on chicken embryo (GHani et al., 1975).
Difference between fertility and hatchability of treatment chickens in treated (13.54) was higher than untreated control (16\%).

Regarding the improved cull percentage in treated than non treated (1.91 and 2.85) and accordingly the number of marketable chicks/1000 hens (667.36 and 637.71) can be due to removal of the effect of aflatoxins on calcium and phosphorus metabolism as reported by (Glahn et al., 1991). Our field study pointed out that the administration of selicate as adsorbent in ration for control of mycotoxins in breeders resulted in slight improvement in reproductive performance in the $1^{\text {st }}$ weeks after administration and over all average weekly egg and hatching egg production, also, hatchery performance data in treated birds was higher than non medicated control. Aluminum silicate was not able to treat flock to reach the farm standard.

Consequently our results indicated that Aluminum silicate was of value but we still in need of more effective products for mycotoxins in breeder chicken flocks especially those showing chronic affection.

\section{References}

Abdullah, A. S. and Lee, O. B. (1981): Aflatoxicosis in ducks. Kajian Vet. 13:33-36.

Anjum, A. D. (1994): Outbreak of infectious bursal disease in vaccinated chickens due to aflatoxicosis. Indian Vet. J.71: 322-324.

Asplin, F. D. and Carnaghan, R. B. A. (1961): The toxicity of certain groundnut meals for poultry with special reference to their effect on ducklings and chickens. Vet. Rec., 73:1215-1219.

Azzam, A. H. and Gabal, M. A. (1997): Interaction of aflatoxin in the feed and immunization against selected infectious diseases. Avian Pathol., 26:317-325.

Azzam, A. H. and Gabal, M. A. (1998): Aflatoxin and immunity in layer hens. Avian Pathol., 27:570-577.

Bacon, C. W.; Sweeney, J. G.; Robbins, J. D. and Burdick, D. (1973): Production of penicillic acid and ochratoxin A on poultry feed by Aspergillus ochraceus: Temperature and moisture requirements. App. Env. Microbiol., 26:155-160.

Bailey, R. H.; Kubena, L. F.; Harvey, R. B.; Buckley, S. A. and Rottinghaus, G. E. (1998): Efficacy of various inorganic sorbents to reduce the toxicity of aflatoxin and T2 toxin in broiler chickens. Poult. Sci., 77: 1623-1630.

Bryden, W. L.; Lloyd, A. B. and Cumming, R. B. (1980): Aflatoxin contamination of Australian animal feeds and suspected cases of mycotoxicosis. Aust. Vet. J., 56:176180.

Bunaciu, P. R.; Tudor, D. S.; Cureu, I. and Bunaciu, P. (1998): The effect of ascorbic acid in the decreasing of negative effects of aflatoxins in broilers. Proc. Europ. Poult. Conf., 10:384-388.

Burns, R. B. and Dwivedi, P. (1986): The natural occurrence of ochratoxin A and its effects in poultry: A review. II. Pathology and immunology. World. Poult. Sci.. J., 42:48-55. 
Choudhury, H.; Carlson, C. W. and Semeniuk, G. (1971): A study of ochratoxin toxicity in hens. Poult. Sci., 50:1855-1859.

Choudary, C. and Rao, M. R. (1982): An outbreak of aflatoxicosis in commercial poultry farms. Poult. Adviser, 16:75-76.

Cottier, G. J.; Moore, C. H.; Diener, U. L. and Davis, N. D. (1969): The effect of feeding four levels of aflatoxin on hatchability and subsequent performance of broilers. Poult. Sci., 48:1797.

Dafalla, R.; Hassan, Y. M. and Adam, S. E. I. (1987): Fatty and hemorrhagic liver and kidney syndrome in breeding hens caused by aflatoxin B1 and heat stress in the Sudan. Vet. and Human Toxicol., 29:252-254.

Dawson, K.A. (2001): The application of yeast and yeast derivatives in the poultry industry. Proc. Aust. Poult. Sci. Symp., 13: 100-105.

Dwivedi, P . and Burns, R. B . ( 1986 ): The natural occurrence of ochratoxin A and its effects in poultry. A review. Part I. Epidemiology and toxicity. World Poult. Sci. J., 42:32-47.

El-Karim, S. A.; Arbid, M. S.; Soufy, A. H.; Bastamy, M. and Effat, M. M. (1991): Influence of metabolite ochratoxin A on chicken immune response. Egypt J. Comp. Pathol. Clin. Pathol., 4(1):159-172.

Gardiner, M. R. and Oldroyd, B. (1965): Avian aflatoxicosis. Aust. Vet. J., 41:272-276.

Glahn, R. P.; Beers, K. W.; Bottje, W. G.; Wideman, R. F.; Huff, Jr., W. E. and Thomas, W.(1991): Aflatoxicosis alters avian renal function, calcium, and vitamin D metabolism. J Toxicol. Env. Hlth., 34:309-321.

GHani, S. H.; Bancroft, I. and O'Rahily, M. (1975): The teratogenic effects of ochratoxin A in the chick embryo. Teratol., 11:18A

Harvey, R. B.; Kubena, L. F. and Phillips, T. D. (1993): Evaluation of aluminosilicate compounds to reduce aflatoxin residues and toxicity to poultry and livestock: A review report. Sci. Total Env. Sup., 93:1453-1457.

Hetzel, D. J. S.; Hoffman, Devan de Ven, J. and Soeripto, S. (1984): Mortality rate and liver histopathology in four breeds of ducks following long term exposure to low levels of aflatoxins. Singapore Vet. J., 8:6-14.

Howarth, B. J. and Wyatt, R. D. (1976): Effect of dietary aflatoxin on fertility, hatchability, and progeny performance of broiler breeder hens. App. Env. Microbiol., 31 :681-684.

Huff, W. E.; Wyatt, R. D. and Hamilton, P. B. (1975): Effects of dietary aflatoxin on certain egg yolk parameters. Poult. Sci., 54:2014-2018.

Huff, W. E.; Doerr, J. A.; Wabeck, C. J.; Chaloupka, G. W. ; May, J. D. and Merkley. J. W. (1983): Individual and combined effects of aflatoxin and ochratoxin $\mathrm{A}$ on bruising in broiler chickens. Poult. Sci., 62:1764-1771.

Huff, W. E.; Kubena, L. F. ; Harvey, R. B. and Phillips, T. D. (1992): Efficacy of hydrated sodium calcium aluminosilicate to reduce the individual and combined toxicity of aflatoxin and ochratoxin A. Poultry Sci., 71:6469.

Jones, F. T.; Hagler, W. H. and Hamilton, P. B. (1982): Association of low levels of aflatoxin in feed with productivity losses in commercial broiler operations. Poult. Sci., 61:861-868.

Kratzer, F. H.; Bandy, D.; Wiley, M. and Booth, A. N. (1969): Aflatoxin effects in poultry. Proc. Soc. Exp. Biol. Med. 131:1281-1284.

Kubena, L. F.; Harvey, R. B.; Phillips, T. D. and Clement, B. A. (1993): Effect of hydrated sodium calcium aluminosilicates on aflatoxicosis in broiler chicks. Poult. Sci., 72:651-657.

National Research Council (NRC) (1984): National requirement for poultry. $9^{\text {th }}$ Ed., Washington DC, National Academy Press.

Niemiec, J.; Borzemska, W.; Roszkowski, J.; Karpinska, E.; Kosowska, G. and Szeleszczuk, P. (1995): Pathological changes in chick embryos from layers given feed contaminated with ochratoxin A. Med Weter 51(9):538-540.

Oloudhury, I.; Culsan, C. W. and Semeniuk, G. (1971): A study of ochratoxin toxicity in hens. Poult. Sci., 50: 18551859.

Page, R. K.; Stewart, G.; Wyatt, R.; Bush, R.; Fletcher, O. J. and Brown, J. (1980): Influence of low levels of ochratoxin A on egg production, egg-shell stains, and serum uric-acid levels in leghorn-type hens. Avian Dis., 24:777780.

Pier, A. C. (1973): Effects of aflatoxin on immunity. J. Am. Vet. Med. Assoc., 163:1268-1269.

Prior, M. G. and Sisodia, C. S. (1978): Ochratoxicosis in white leghorn hens. Poult Sci., 57:619-623.

Prior, M. G.; Sisodia, C. S. and O'Neil, J. B. (1981): Effects of ochratoxin A on egg production, body weight and feed intake in white leghorn hens. Poult Sci., 60:1145-1148. Saif, Y. M.; Barnes, H. J.; Fadly, A. M.; Glisson, J. R. and Swayne, D. E. (2003): Poultry Diseases, $11^{\text {th }}$ ed., Iowa State Press, Iowa.

Shoyinka, S. V. O. and Onyekweodiri, E. O. 1987): Clinicopathology of interaction between aflatoxin and aspergillosis in chickens. Bullt. Animal Hlth Prod. Afr., 35:47-51.

Soares, L. M. and Rodrigez-Amaya, D. B. (1989): Survay of Aflatoxin, Ochratoxin A, Zeralenone and Steringmatocystin in some brazilian foods by using multitoxin thinlayer chromatographic method. J. Assoc. Off. Anal. Chem., 72: 22-26.

Tohala, S. H. (1983): A study of ochratoxin toxicity in laying hens. Dise Abstr B Sci. Eng., 44:655.

Uraguchi, K. and Yamazaki, M. (1978): Toxicology, Biochemistry and Pathology of Mycotoxins. Halsted Press, John Wiley and Sons: New York, 1-106.

Wyatt, R. D. and Hamilton, P. B (1975): Interaction between Aflatoxicosis and a natural infection of chickens with Salmonella. Appl. Microbiol., 30:870-877. 
دراسة حقلية عن تأئير سلكات الألمنيوم كممع للسموم الفطرية على إنتاجية أمهات دجاج التسمين عمر 1 ه أسبوع

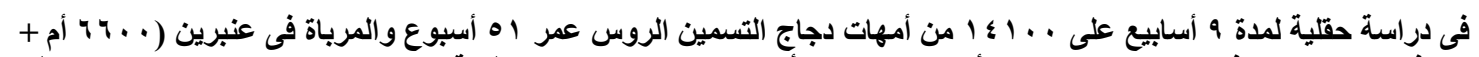

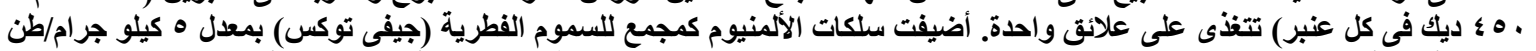

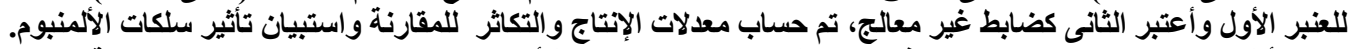

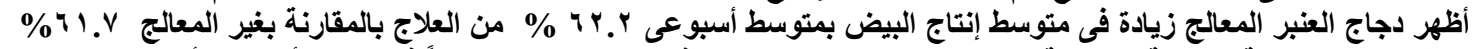

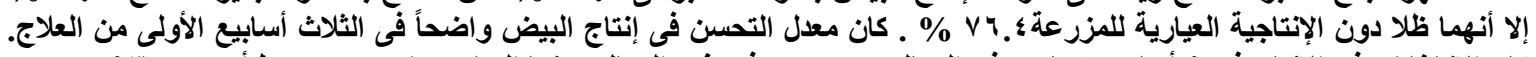

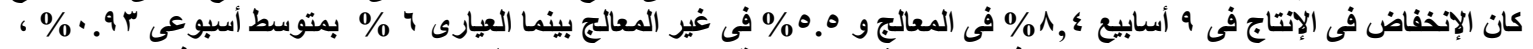

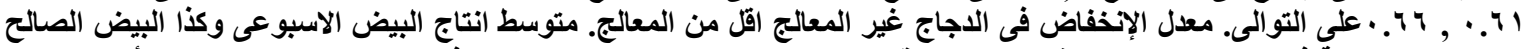

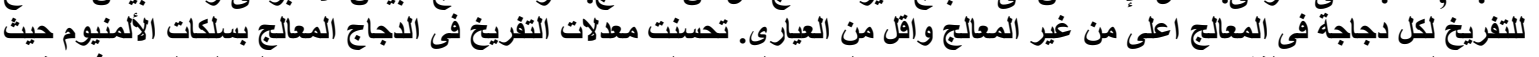

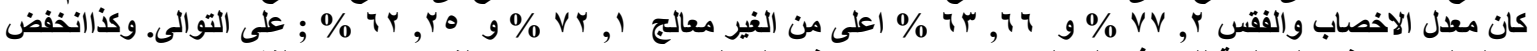

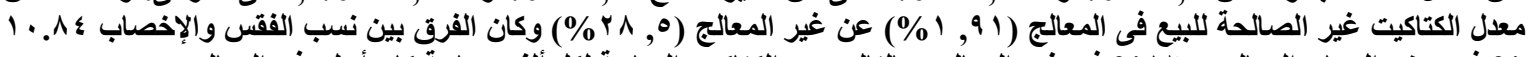

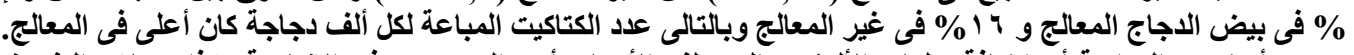

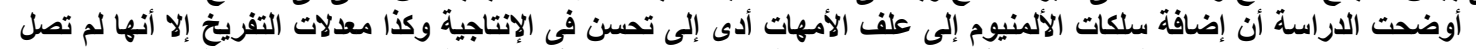

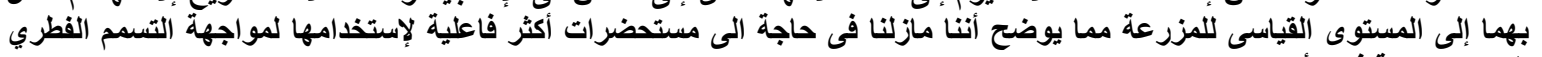

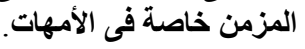

